\title{
Archéopages
}

Archéopages Archéologie et société

$44 \mid 2017$

Terrains vagues

\section{Tombe à crémation dans une église}

\section{Didier Paya et Jérôme Rouquet}

\section{OpenEdition}

Journals

Édition électronique

URL : https://journals.openedition.org/archeopages/1596

DOI : 10.4000/archeopages. 1596

ISSN : 2269-9872

\section{Éditeur}

INRAP - Institut national de recherches archéologiques préventives

\section{Édition imprimée}

Date de publication : 1 juin 2017

Pagination : 88-89

ISSN : 1622-8545

\section{Référence électronique}

Didier Paya et Jérôme Rouquet, «Tombe à crémation dans une église », Archéopages [En ligne], 44 | 2017, mis en ligne le 01 juillet 2019, consulté le 15 juin 2021. URL : http://journals.openedition.org/ archeopages/1596; DOI : https://doi.org/10.4000/archeopages.1596 


\section{Tombe à crémation dans une église}

Didier Paya

Inrap, UMR 5288 «AMIS »

responsable d'opération

Jérôme Rouquet

Inrap, UMR 5199 «PACEA »

étude de la sépulture

Site

Église Saint-Martin de Peyrelade Saverdun

Ariège

Date

2014 et 2015
Le prieuré Saint-Martin de

Peyrelade, dépendant de l'abbaye de Lézat, a été fondé au XI ${ }^{\mathrm{e}}$ siècle, sur un site déjà occupé durant l'Antiquité [ill. 1]. Au début du XıII ${ }^{\mathrm{e}}$ siècle, l'église du prieuré-cure est reconstruite. Sa fonction funéraire se développe jusqu'à la destruction de l'édifice vers 1574 par les protestants, qui occupent la ville voisine de Saverdun jusqu'en 1579 (Tranier, 2012). Parmi les tombes découvertes à l'intérieur du bâtiment [ill. 2], la sépulture 43 a particulièrement attiré l'attention. Il s'agit d'un lot d'ossements humains brûlés, déposé sur la face concave d'une tuile canal et couvert par une autre tuile [ill. 3].

La présence d'une sépulture à crémation surprend dans ce contexte, pour deux raisons. La première est que l'incinération a disparu au cours du Bas-Empire car, comme les derniers païens, les premiers chrétiens pratiquaient l'inhumation. L'Église n'a cependant interdit l'incinération qu'en 1887 (interdiction durant jusqu'en 1963). Avant cette date, seul le Capitulaire saxon, en 785 , avait condamné la crémation des corps sous peine de mort ; il s'agissait alors de forcer les populations païennes conquises à adopter des pratiques considérées comme chrétiennes. La seconde raison est que, si la condamnation au bûcher a eu cours pendant les périodes médiévale et moderne, on imagine mal les restes d'un condamné inhumé dans une église.

Une tentative de datation par le radiocarbone s'étant avérée infructueuse, il est impossible de dater le décès du sujet. La datation de cette tombe est donc établie en fonction du contexte archéologique et historique. L'aménagement du dépôt de crémation doit être contemporain de deux autres tombes, situées à proximité : la sépulture d'un homme mort d'avoir reçu trois coups taillants à la tête et une autre contenant une monnaie d'Henri III, émise à partir de 1575 (étude V. Geneviève, Inrap).

Certaines caractéristiques de l'individu dont les os ont été incinérés sont identifiables. Il s'agit d'un sujet adulte, robuste, dont le sexe n'a pu être déterminé, et qui souffrait d'une atteinte infectieuse au niveau des côtes. La perte ante mortem des prémolaires et molaires inférieures gauches et les remodelages arthrosiques observés sur une vertèbre cervicale semblent indiquer un âge avancé.

Pour interpréter ce dépôt surprenant, il était important de tenter de déterminer si la crémation a été effectuée sur un corps frais, complet, décharné, ou sur des os anciens. Les os découverts, très fragmentés, sont d'une coloration variant du noir au blanc [ill. 4]. La majeure partie d'entre eux présentent des fractures rectilignes et peu de déformations, ce qui est plutôt lié à une calcination d'os secs ; la variété de coloration des os, les fractures curvilignes et les. microfissurations indiqueraient,

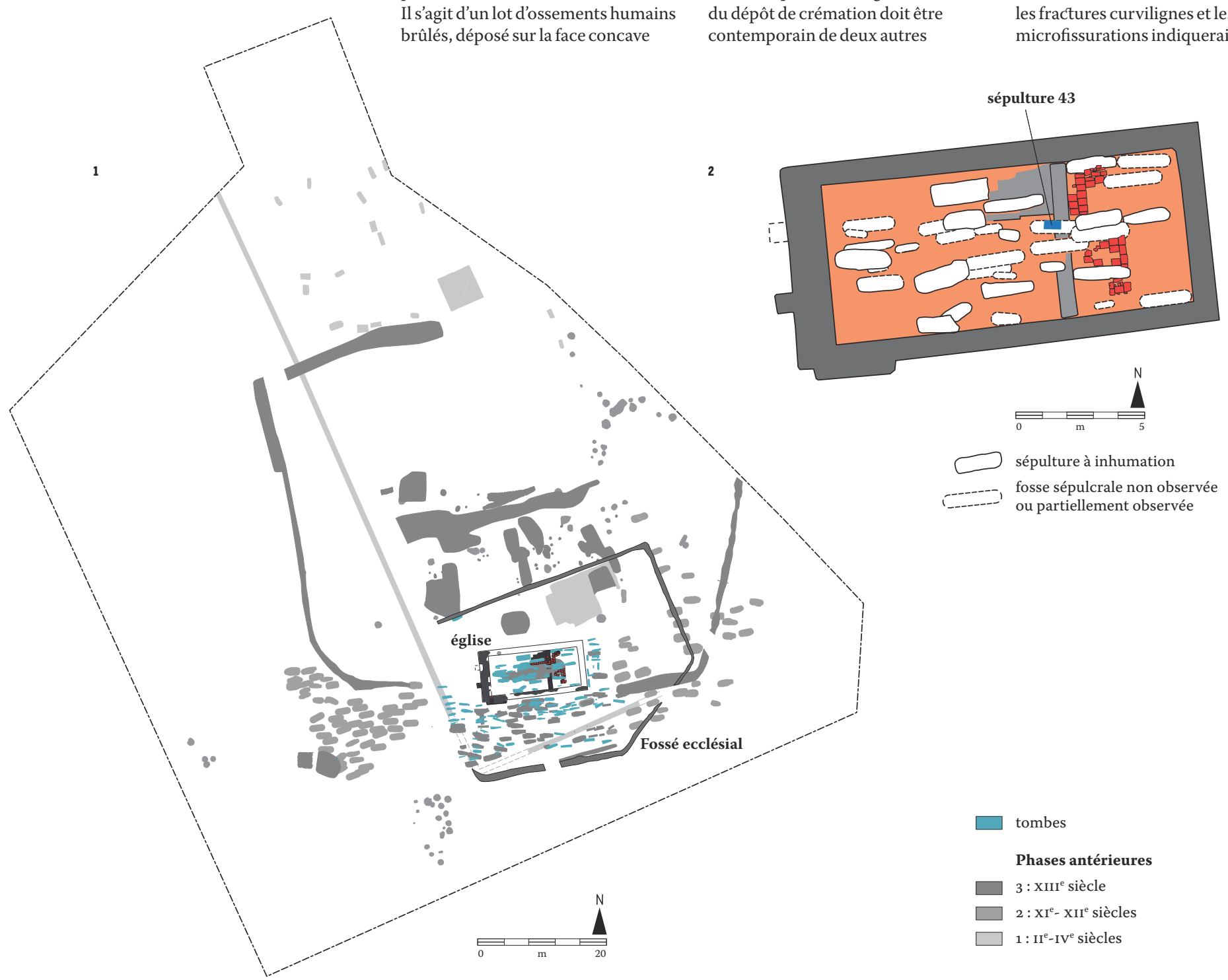




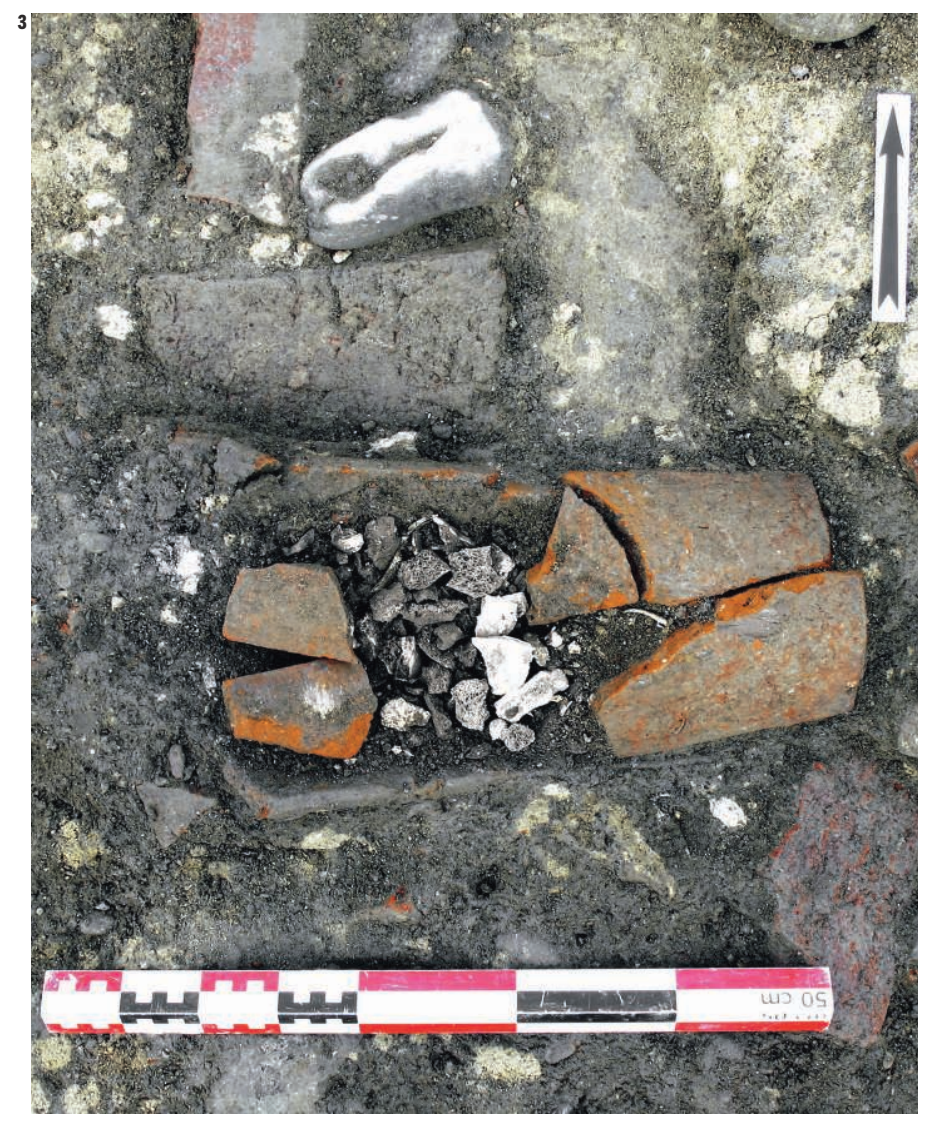

en revanche, une crémation d'os frais, possiblement entourés de chair. Cependant, la coloration des os majoritairement grise à gris-bleu caractérise une exposition à des températures basses (de 300 à $600^{\circ} \mathrm{C}$ ) qui s'accordent mal avec ce que l'on rencontre lors de crémations de corps. Quant au poids total d'ossements recueillis, il sélève à $568,1 \mathrm{~g}$, ce qui est très inférieur au poids moyen de l'incinération d'un corps adulte (entre 1761,1 g et 2242 g). Si la sépulture provient d'une crémation à vocation funéraire, seule une petite partie des restes osseux aurait donc été prélevée sur le bûcher funéraire. La grande fragmentation des ossements nuit à leur identification, mais on constate quand même une surreprésentation, certes modérée, de la tête et du tronc. Les os de ces zones sont plus facilement reconnaissables, ce qui rend impossible d'affirmer qu'il s'agisse là des effets d'un ramassage préférentiel.

L'absence du moindre fragment de charbon dans le dépôt est une donnée remarquable, dans la mesure où la crémation d'un corps frais nécessite une quantité de bois considérable. Cette absence implique un prélèvement particulièrement précautionneux et/ou un nettoyage des vestiges prélevés sur le bûcher.

Bien que ces données ne permettent pas une interprétation incontestable, nous pensons que ce dépôt peut être mis en relation avec des pratiques en cours lors des guerres de Religion et relatées dans les textes. Il s'agit de la destruction par les protestants des «ossa sacra », symboles d'idolâtrie, et de la récupération par les catholiques de ce qui pouvait être sauvé des reliques (Crouzet, 2009). Des corps ayant été inhumés dans l'église en partie détruite, n'a-t-on pas voulu replacer très précautionneusement dans ce bâtiment des reliques qui auraient été jetées sur un bûcher?

\section{Références bibliographiques}

Crouzet D., 2009, «Sur le

désenchantement des corps saints au temps des troubles de religion ", in Fabre P.-A., Boutry P., Julia D. (éd.), Reliques modernes. Cultes

et usages chrétiens des corps saints des Réformes aux révolutions,

Paris, Éditions de l'EHESS, vol. 2, p. 435-482.

Tranier E., 2012, Frayras, Ariège, Saverdun, rapport d'opération, Inrap-SRA Midi-Pyrénées, 124 p.

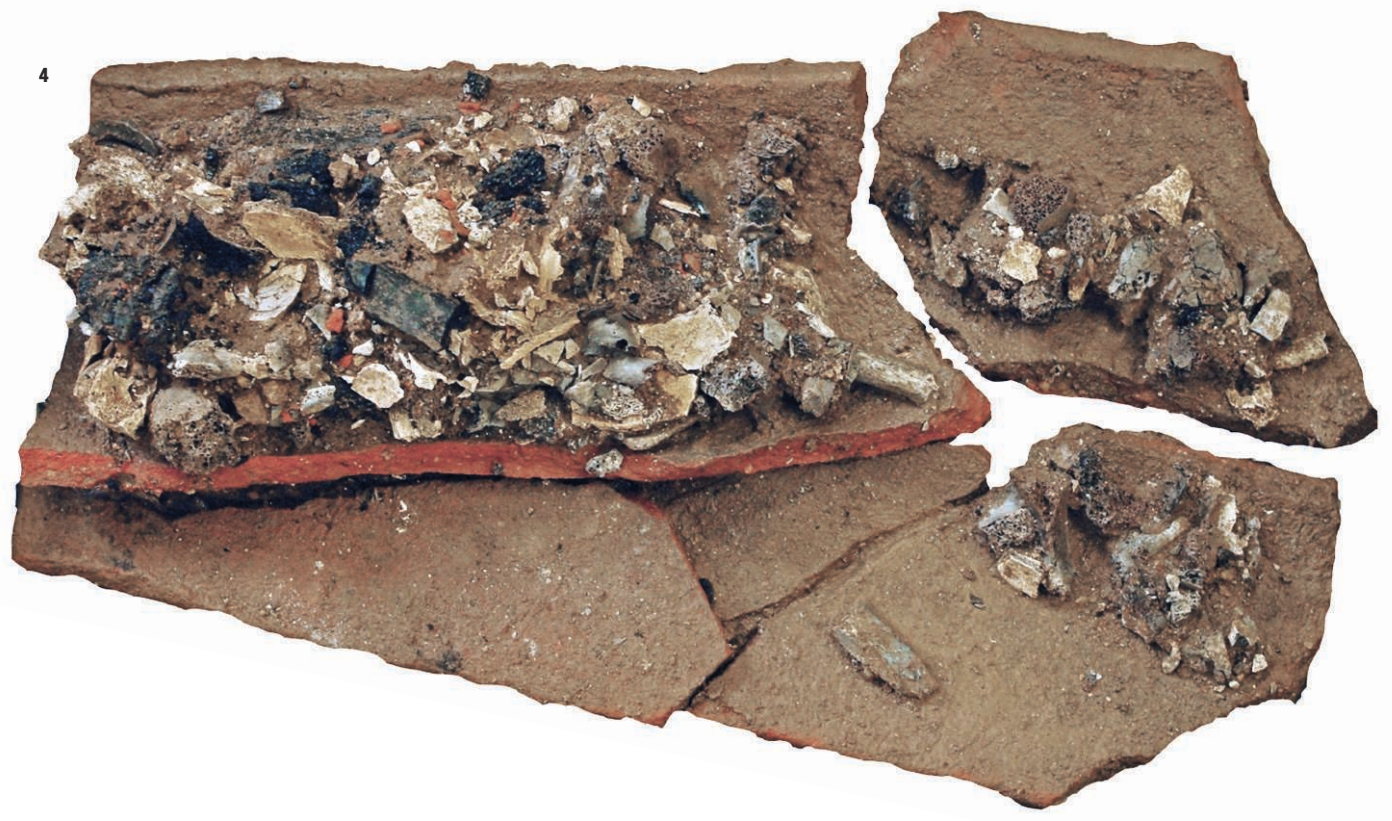

1. Plan de la quatrième

et dernière phase

d'occupation du site

(xive-xvie siècles), les tombes

qui apparaissent en bleu

correspondent à cette

dernière.

2. Localisation de

la découverte dans I'église

3. La sépulture 43 après

un premier nettoyage.

4.Vue générale du premier

décapage, avant prélèvement. 